\title{
XLVII. On the measurement of mutual inductance by the aid of a vibration galranometer
}

\section{Albert Campbell B.A.}

To cite this article: Albert Campbell B.A. (1907) XLVII. On the measurement of mutual inductance by the aid of a vibration galranometer , Philosophical Magazine Series 6, 14:82, 494-503, DOI: $10.1080 / 14786440709463708$

To link to this article: http://dx.doi.org/10.1080/14786440709463708

曲 Published online: 16 Apr 2009.

Submit your article to this journal $\lceil\pi$

Џll Article views: 2

Q View related articles $\square$

Citing articles: 1 View citing articles 5 


\section{$494]$}

XLVII. On the Measurement of Mutual Inductance by the Aid of a Vibration Galranometer. By Albert Cami'Bell, $B, A$ * (From the National Physical Laboratory.)

[Plate XII.]

1. Introductory.

Contents.

2. 'Theory of Modified Carey Foster Method.

3. Vibration Galvanometer.

4. Moving Coil Vibration Galvanometer.

5. Practical Working of Galvanometer and Hughes-Rayleigh

Method adapted to Measuring Frequency.

6. Results obtained by Carey Foster Method.

\section{Introductory.}

THE determination of a self inductance by comparing it with a condenser by means of Anderson's Method can be made with ease and accuracy, as the two adjustments are independent. The use of a vibration galvanometer in this method as carried out by Rosa and Grover (Bulletin of the Bureau of Standards, vol. i. p. 291, 1905) greatly increases the ease of manipulation and the sensitivity of reading. For several years past we have tested our standards of mutual inductance against the B.A. Standard Air Condensers (as well as Mica Standards) which have been standardized by Maxwell's Commutator Method. For this purpose I have used Carey Foster's Method †, in which (as in Anderson's Method) the adjustments are easy and the formula simple. The connexions are shown in fig. 1 .

Fig. l.

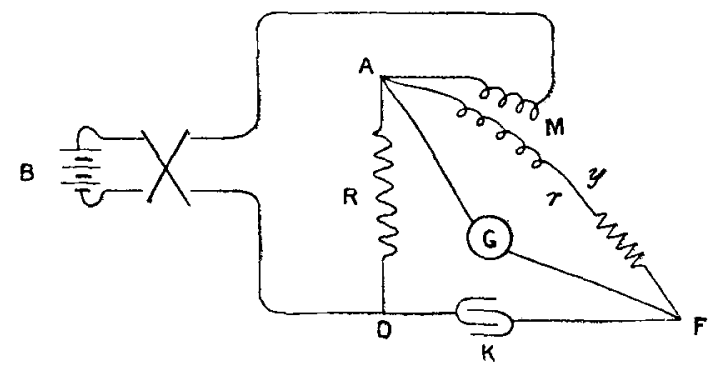

$R$ is a non-inductive resistance (capable of carrying a fair amount of current); $M$ is the mutual inductance to be

* Communicated by the Physical Society : read May 24, 1907.

t Phil. Mag. [5] vol, xxiii. p. 121, Feb. 1887. 
mensured, its secondary coil being in series with an adjustable resistance in the branch $\mathrm{A} y \mathrm{~F} ; \mathrm{K}$ is a condenser, and $\mathrm{G}$ a ballistic galvanometer. When there is no throw on $\mathrm{G}$ on reversing the battery then

$$
\mathrm{M}=10^{-6} \mathrm{KR} r \text {, }
$$

where $M$ is in henries and $K$ in microfarads, and $r$ is the resistance of the branch $\mathrm{A} y \mathrm{~F}$. To increase the sensitivity a secohmmeter arrangement was sometimes used. Knowing the value of the vibration galvanometer in other cases, I attempted to apply it to this one, but found that the method had to be modified in order to make it applicable. I found later that the modification I had introduced had been already suggested by Rowland *. As the use of the vibration galvanometer, however, is a great advantage (and novel in this method, so far as I know), I think it will be of interest to describe the complete method.

\section{Theory of Modified Carey Foster Method.}

In fig. 2 let $Q$ be a source of alternating current and $G$ a vibration galvanometer or its equivalent. The necessary modification consists in adding a resistance $S$ in series with the condenser $K$. Let the resistances of the other branches

Fig. 2.

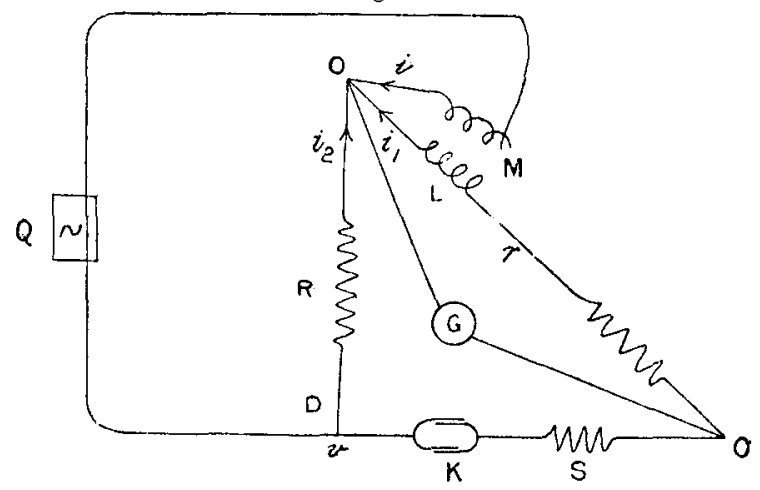

be $\mathrm{R}$ and $r$, and let the instantaneous values of the currents be $i, i_{1}$, and $i_{2}$ as marked. Let the instantaneous potentials on the terminals of the galvanometer $G$ be 0 and 0 , so that there is no deflexion (i.e. the condition of balance is to hold at every instant). Let $v$ be the instantaneous value of the potential at $\mathrm{D}$, and $q$ the charge in the condenser.

* Phil. Mag, [5] vol, xlv. pp. 65-85 (1898). 
496 Mr. A. Campbell on the Measurement of Mutual

Then

and

$$
i=-i_{1}-i_{2}
$$

$$
\begin{aligned}
0 & =i_{1} r+\mathrm{L} \frac{d i_{1}}{d t}+\mathrm{M} \frac{d i}{d t} \\
& =i_{1} r+\mathrm{L} \frac{d i_{1}}{d t}-\mathrm{M} \frac{d i_{1}}{d t}-\mathrm{M} \frac{d i_{2}}{d t} . \quad . \quad . \quad
\end{aligned}
$$

Also

$$
\begin{aligned}
v & =i_{2} \mathrm{R}, \\
q & =\mathrm{K}\left(v-i_{1} \mathrm{~S}\right), \\
i_{1} & =\dot{q}=\mathrm{K}\left(\dot{v}-\mathrm{S} \frac{d i_{1}}{d t}\right) ; \\
\therefore \quad v & =\frac{i_{1}}{\mathrm{~K}}+\mathrm{S} \frac{d i_{1}}{d t} .
\end{aligned}
$$

So

therefore

$$
i_{2} \mathrm{R}=v=\text { const. }+\int \frac{i_{1}}{\mathrm{~K}} d t+\mathrm{SK} i_{1} ;
$$

$$
\mathrm{R} \frac{d i_{2}}{d t}=\frac{i_{1}}{\mathrm{~K}}+\mathrm{S} \frac{d i_{1}}{d t} .
$$

Substituting in (1) we have

$$
i_{1}\left(r-\frac{\mathrm{M}}{\mathrm{RK}}\right)+\left(\mathrm{L}-\mathrm{M}-\frac{\mathrm{MS}}{\overline{\mathrm{R}}}\right) \frac{d i_{1}}{d t}=0 .
$$

Now, as will be shown below, we may assume all the currents to be sinusoidal, i. e., $i_{1}=\mathrm{I}_{\mathrm{r}} \sin p t$, and hence

$$
r-\mathrm{M} / \mathrm{RK}=0 \text { and } \mathrm{L}_{-}-\mathrm{M}-\frac{\mathrm{MS}}{\mathbf{R}}=0 .
$$

Thus for a balance we must have the following two conditions satisfied, viz. :

$$
\mathrm{M}=10^{-6} \mathrm{KR} r, \quad \text {. . . . }
$$

and

$$
\mathrm{L}=\mathrm{M} \frac{\mathrm{R}+\mathrm{S}}{\mathrm{R}} ; \ldots . . .
$$

where $\mathrm{K}$ is in microfarads. When $\mathrm{S}=0, \mathrm{~L}=\mathrm{M}$; and this is therefore the minimum permissible value for $\mathrm{L}$. When $\mathrm{L}$ is less than $M$ in the pair of coils under test, a third inductive coil must be inserted in the branch $\mathrm{OrO}$ to bring the value of $\mathrm{L}$ up to at least M, otherwise no balance can be obtained. It will be noticed (a) that if $\mathrm{R}$ be kept constant the conditions (2) and (3) can be satisfied by independent adjustments 
Inductance by the Aid of a Vibration Galvanometer. 497 of $\mathrm{K}$ or $r$ and $\mathrm{S}$; (b) that the adjustments are independent of the frequency. Accordingly a balance can always be obtained with great facility *.

\section{Vibration Galzanometers.}

Since Vibration Galvanometer methods are familiar to very fow experimenters in this country, I think the following general description will be of interest.

By a Vibration Galvanometer is meant one in which the natural vibration frequency of the moving part can be adjusted to be the same as the frequency of the source of alternating or pulsating current used. The two main advantages in using a tuned galvanometer or other instrument are as follows:-(a) when the instrument is in tune with the source of current the vibratory motion of the moving part is enormously increased, due to resonance; thus a high sensitivity is obtained, usually about 100 times greater than that without tuning. (b) Since the sensitivity is so very much greater for the proper frequency than for others, when the wave form is other than a sine curve the instrument, if tumed to the fundamental frequency, responds to this, and is practically unaffected by the harmonics ; if the instrument is tuned to one of the harmonics instead, all but this component is practically ignored by it. For this reason the theory of each method in which a tuned instrument is used can be worked out on the assumption that the wave forms of voltage and current are all pure sine curves.

The deflexion is usually proportional to the amplitude.

This use of a tuned instrument in null methods is, I believe,

* The above investigation can be carried out more readily by the use of the operators $\mathrm{L} p \sqrt{-1}$ and $1 / K_{p} \sqrt{-1}$, but to some readers the method given will be clearer.

Equation (1) becomes

$$
\left(r+\mathrm{L} p \sqrt{-1}-\mathbf{M}_{p} \sqrt{-1}\right) i_{3}=\mathrm{M}_{p} \sqrt{-1} \cdot i_{2} ;
$$

and the next equations give

Hence

$$
\mathrm{R} i_{2}=\left(\mathrm{S}-\frac{\sqrt{-1}}{\mathrm{~K} p}\right) i_{\mathrm{i}} .
$$

$$
\mathrm{R}(r+\mathrm{L} p \sqrt{-1}-\mathrm{M} p \sqrt{-1})=\mathrm{M} p \sqrt{-1}\left(\mathrm{~S}-\frac{\sqrt{-1}}{\mathrm{~K} p}\right)
$$

Separating the real and imaginary parts we have

$$
\begin{aligned}
\mathrm{M} & =\mathrm{KL} r \\
\text { and } \quad \mathrm{L} & =\mathrm{M} \frac{\mathrm{R}+\mathrm{S}}{\mathbf{R}} \quad \text { as before. }
\end{aligned}
$$


due to Max Wien *, in one of whose papers (Wied. Ann.xliv. p. 689,1891 ) will be found a very complete discussion of a number of his methods of measuring inductance and capacity.

In all his earlier experiments the tuned instrument was an "Optical Telephone," in which the motion of the diaphragm was magnified by the use of a small mirror with light spot and scale. The sensitivity of this was $3 \times 10^{-7}$ amp. per mm. at $1 \mathrm{~m}$.

In 1896 Rubens's Vibration Galvanometer appeared †; it consists of a series of very small magnets or soft-iron needles fastened to the middle of a tightly strung torsion wire and in a field due to two strong permanent magnets, round whose pole-pieces are coils carrying the alternating current to be measured. The tuning is effected by altering the effective length of the clamped torsion wire and by adjustment of the magnets, and the sensitivity obtained is said to be four times greater than that of the optical telephone.

Some years later $\ddagger$ M. Wien brought out a more sensitive form, in which the small magnet system is between the poies of a small electromagnet magnetized entirely by the current to be measured.

\section{Moving Coil Vibration Galvanometer.}

After using an instrument of the Rubens type for some tine, I designed another of moving coil type, which I have found more convenient.

It consists of an electromagnet (or permanent magnet) with a rather narrow air gap in which is suspended a very light and small coil with bifilar control, which can be regulated by altering the tension by means of an adjustable spring or weight (as in some oscillographs).

Fig. 3.

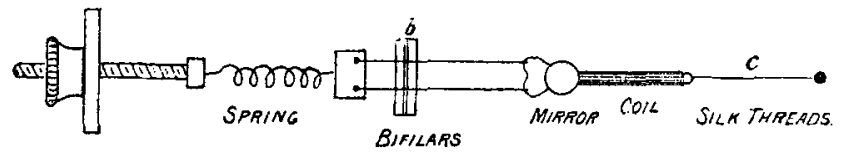

In fig. 3 is shown one arrangement of the suspended system which I have used (shown horizontally for convenience of printing).

* Max Wien, Wied. Ann. xlii. p. 593 (1891); xliv. p. 681 (1891); xliv. p. 689 (1891); lvii. p. 249 (1896); lviii. p. 353 (1898). See also E. Orlich, Elektrotechn. Zeitschr. vol. xxvi. (1903).

† Rubens, Wied. Ann. lvi. p. 27 (1896).

$\neq$ M. Wien, Ann. der Physik, iv. p. 425 (1901). 
Below the coil is a fastening of one or more silk threads $c$. The range of frequency obtainable depends on the moment of inertia of the moving part, the tension, width of bifilars, \&c. In one specimen the ordinary range (from 50 to 100 per sec.) can be obtained by simply tightening or loosening the spring by the screw adjustment, while by placing an adjustable bridge $b$ (fig. 3) under the bifilars the range can be extended to 700 or $800 \sim$ per sec. The readiness with which the frequency can be adjusted appears to be one of the advantages in the bifilar type. As the frequency is raised the sensitivity decreases in the inverse ratio. With given magnetic field, in normal use (i. e. with resonance) the sensitivity only depends on the damping moment, which is both mechanical and electrical. For example, if the moment of inertia and the control torque be both increased in the same proportion without altering the damping, then both the frequency and the sensitivity remain unchanged. It is of importance, therefore, to keep the damping small. For many purposes at frequencies of 20 to $200 \sim$ per second, sufficient sensitivity can be obtained even when using a fairly large mirror (1 $\mathrm{cm}$. diameter), but for higher frequencies it is advisable to reduce this size considerably. The control torque is usually strong, the tension being of the order of 0.5 to $1 \mathrm{kgm}$.

\section{Practical Working of Galvanometer and Ilughes-Rayleigh Method.}

The best type of current to use is a nearly pure sine-curve altermating current of very steady frequency (see Rosa and Grover above), but an interrupted current can be used with good accuracy. It is desirable to be able to set the frequency of the current by gradual and fine adjustment for the exact tuning, and for this purpose a wire interrupter like that of Wien is effective. It is merely a monochord solidly supported with fine adjustment of tension and maintained electrically with a mercury break as tuning-forks are. When the galvanometer is in resonance (which is known by the maximum elongation of the spot of light with a given current), it does not follow that it is responding to the fundamental trequency given by the wire ${ }^{*}$; it may be in resonance with one of the larmonics. In order to determine the actual frequency to which it is answering, a usual method is to test it by a

* It is a curious fact that a Rubens Galvanoneter with given control sometimes has two points of resonance near one another, e. $y .40$ and 48 - per second in one specimen. (See also Rosa and Grover, loc. cit.) 
eondenser and a variable self-inductance brought to resonance. Another method which I have found very convenient for the same purpose is that of Hughes's Inductance Bridge * as developed by Lord Rayleigh + , in which a mutual inductance is compared against an independent selfinductance.

'lixe connexions are shown in fig. 4, where $M$ is a variable mutual inductance; $\mathrm{L}$ a self-inductance of resistance $\mathrm{P} ; \mathrm{Q}$, $R$, and $S$ non-inductive resistances; $\mathrm{E}$ : source of alternating or interinittent current of steady frequency; and $G$ the

Fig., 4.

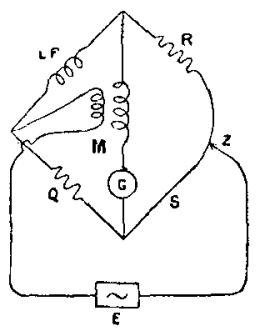
vibration galvanometer.

$\mathrm{R}+\mathrm{S}$ is kept constant, $\mathrm{Z}$ being a slider by which $\mathrm{S}$, which is entirely a slide-wire, can be gradually varied down to zero.

As Lord Rayleigh has shown, the conditions for a balance are

and

$$
\begin{aligned}
& \mathrm{QR}-\mathrm{SP}=p^{2} \mathrm{ML} \quad \text {. . . . . } \\
& \mathrm{M}(\mathrm{P}+\mathrm{Q}+\mathrm{R}+\mathrm{S})=\mathrm{SL}, \text {. . . . . }
\end{aligned}
$$

where $p=2 \pi n, n$ being the frequency.

Let $Q$ as well as $R+S$ have a fixed value. For good sensitivity the resistance $\mathrm{P}$ usually will have a temperature coefficient not negligible, as the whole or part of the arm may be of copper.

Two cases arise according as we consider $P$ (1) known and constant, or (2) only approximately known and variable.

Case 1.-Let $P$ be constant, and hence

$$
\text { also } \begin{aligned}
\mathrm{P}+\mathrm{Q}+\mathrm{R}+\mathrm{S} & =\text { const. }=a \text { (say); } \\
\mathrm{R}+\mathrm{S} & =b .
\end{aligned}
$$

Let $I_{1}$ also be constant and known, and let a balance be obtained by varying $\mathrm{M}$ and the position of $\mathrm{Z}$.

'Then we have

$$
\begin{aligned}
(2 \pi n)^{2}=p^{2} & =\frac{a}{\mathrm{~L}^{2}}\left(\frac{\mathrm{QR}}{\mathrm{S}}-\mathrm{P}\right) \\
& =\frac{a}{\mathrm{~L}^{2}}\left\{\frac{\mathrm{Q}(b-\mathrm{S})}{\mathrm{S}}-\mathrm{P}\right\} . .
\end{aligned}
$$

Thus $n$ is expressed in terms of the single variable $\mathrm{S}$, and the slide-wire may be marked directly with the values of the frequency deduced from (6).

If wide range of frequencies is to be dealt with, various

* Prof. E. D. Huqhes, Jour. Inst. Elect. Eng. xv. p. 6, Jan. 1886.

+ Lord Rayleigh, Phil. Mag. Dec. 1886. 
Inductance by the Aid of a Vibration Galvanometer. 501 values may be given to $L$. Thus, if $L$ be changed to some sub-multiple $\mathrm{L} / q$, the scale readings for $n$ will merely have to be multiplied by $q$ throughout, provided that $\mathrm{P}$ is kept constant. Perhaps a better way is to keep L unchanged, and alter $\mathrm{P}+\mathrm{Q}$ and $\mathrm{R}+\mathrm{S}$ each in the ratio $1: q$, the alterations being made in $\mathrm{P}$ and $\mathrm{R}$ only, leaving $\mathrm{Q}$ and $\mathrm{S}$ as before; from formula (6) it will be seen that, for the same scale reading, $n$ will become $q n$. The value of the variable $\mathbb{M}$ does not require to be known. The following example, giving values which $I$ have actually used, may be of practical interest. $\mathrm{P}=25$ ohms, $\mathrm{Q}=5$ ohms, $\mathrm{R}+\mathrm{S}=4$ ohms, $\mathrm{L}=0 \cdot 1066$ henry. The graduation of the slide-wire corresponds to Table $I$.

TABLE I.

\begin{tabular}{|c|c|c|}
\hline$n$. & s. & $\begin{array}{l}\text { Temperature- } \\
\text { coefficient } \\
\text { of } n .\end{array}$ \\
\hline $\begin{array}{c}\text { per sec. } \\
10 \\
15 \\
20 \\
30 \\
40 \\
50 \\
60 \\
70 \\
80 \\
90 \\
100 \\
110 \\
120\end{array}$ & $\begin{array}{l}\text { ohm. } \\
0 \cdot 642 \\
0 \cdot 608 \\
0.562 \\
0.471 \\
0 \cdot 392 \\
0 \cdot 320 \\
0 \cdot 260 \\
0 \cdot 213 \\
0.175 \\
0 \cdot 147 \\
0 \cdot 126 \\
0.107 \\
0.090\end{array}$ & $\begin{array}{c}\% \text { per degree C. } \\
-0.43 \\
-0.32 \\
-0.21 \\
-0.08 \\
-0.01 \\
+0.04 \\
+0.08 \\
+0.09 \\
+0.10 \\
+0.11 \\
+0.11 \\
+0.12 \\
+0.12\end{array}$ \\
\hline
\end{tabular}

Since $M=0.00313 \mathrm{~S}$, its range of variation will be from about 2 millihenries at $n=0$ down to about $0 \cdot 28$ millihenry at $n=120$.

This case is usually sufficient to discriminate the actual frequency to which the galvanometer is responding, the exact frequency of the source being determined by comparison with a standard fork or stroboscopically.

Case 2.- If $\mathrm{P}$ be not exactly known, a temperature correction may be applied to the scale readings. Thus in the above example, in which $\mathrm{P}$ was entirely of copper, the temperature coefficients of $n$ at various points of the scale are shown in the third column of Table 1. It will be noticed that the correction may become large only below 30 - per second.

If the variable $M$ has been accurately calibrated, $p$ may be obtained by the equation

$$
p^{2}=\frac{(\mathrm{Q}+\mathrm{S})(\mathrm{R}+\mathrm{S})}{\mathrm{ML}}-\left(\frac{\mathrm{S}}{\mathrm{M}}\right)^{2} . . .
$$


For example, the interrupter was tuned to unison with a standard fork which gave 119.9 per sec.: with $\mathrm{L}=$ $0 \cdot 1000$ henry the method gave $n=120 \cdot 0$ and $119 \cdot 8 \sim$ per sec. in two observations.

Although I have described this method as used for determining the frequency to a first approximation, it can be used, with an accurately known frequency, to determine $\mathrm{I}$ and $\mathrm{M}$ in terms of $\mathrm{P}, \mathrm{Q}, \mathrm{R}, \mathrm{S}$, and $n$; and the use of the vibration galvanometer avoids the difficulty of obtaining a pure sine-curve current.

\section{Results obtained by Modified Carey Foster Method.}

A series (A) of careful tests were made by this method on a standard mutual inductance of nominal value 0.05 henry. This standard consists of a pair of coils of silk-covered wire wound in two deep channels turned on a cylinder of marble, the whole being soaked in hot paraffin wax after winding. It is illustrated in Plate XII.

It was originally adjusted by Carey Foster's method, using a ballistic galvanometer with an air condenser as standard. A series (B) of tests were made on it, using Carey Foster's Method with a secohmmeter commutator.

It was also tested (C) by a quite independent method, viz., Kirchhoff's Absolute Method with a ballistic galvanometer *.

In Table II. are shown some of the results of these sets of tests.

TABLE II.

\begin{tabular}{|c|c|c|c|c|c|c|}
\hline Ect. & Condenser. & K. & R. & & $\begin{array}{l}\text { Mean } \\
\text { of set. }\end{array}$ & $\begin{array}{l}\text { Greatest } \\
\text { error trom } \\
\text { mean of set. }\end{array}$ \\
\hline A $\ldots$ & & $\begin{array}{c}\text { mfd. } \\
0.9994\end{array}$ & $100 \cdot 00$ & & & Parts in 10,000 \\
\hline & $", \quad \cdots$ & $\begin{array}{l}0.8003 \\
0.5003\end{array}$ & $"$ & $\begin{array}{l}0.05008 \\
0.05010\end{array}$ & 0.05009 & 2 \\
\hline B $\quad \ldots$. & Air .............. & 004165 & 20 & 0.05008 & & \\
\hline & 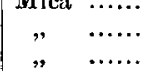 & $\begin{array}{l}0.5000 \\
0.5000\end{array}$ & $\begin{array}{l}50 \\
50 \\
20\end{array}$ & $\begin{array}{l}0.05013 \\
0.05008\end{array}$ & $\{005010$ & 6 \\
\hline C $\ldots \ldots$ & ........... & ........... & $\ldots \ldots$ & $\begin{array}{l}\mathbf{0} \cdot 05019 \\
0 \cdot 00013 \\
0 \cdot 05014 \\
0 \cdot 05011 \\
0 \cdot 05013 \\
0 \cdot 05015 \\
0 \cdot 05016\end{array}$ & 0.05014 & 10 \\
\hline
\end{tabular}

* Maxwell's Elect. \& Mag. vol, ii. \$759; Kirchhoff, Pogg. Ann. Ixxvi. A pril 1849; and Glazebrook, Sargant, \& Dodds, Phil. Trans. pp. 223-268 (1883). 
In sets (A) and (B) the frequency was of the order of 40 and $100 \sim$ per second respectively.

The agreement of sets (A) and (B) appears satisfactory ; while the slightly higher result given by $(\mathrm{C})$ is probably within the limits of possible error of the method as used*. The readings in (A) were sensitive to 2 or 3 in 10,000 . The resistance $\mathbf{R}$ was specially wound to avoid capacity and inductance. An inductince of $0 \cdot 1000$ henry was added in the branch $\mathrm{OrO}$. The total self-inductance of this branch by comparison with our standard inductances was 0765 henry.

Hence, by (3),

$$
\mathrm{M}=\mathrm{L}\left(\frac{\mathrm{R}}{\mathrm{R}+\mathrm{S}}\right)=\frac{0.765 \times 100}{1525.5}=0.0511 \text { henry, }
$$

which is good agreement with the results given by the formula

$$
\mathrm{M}=10^{-6} \mathrm{KR} r \text {. }
$$

Thus we infer that in the mica condenser used there is no appreciable apparent series resistance such as Rowland and other experimenters found in some cases.

I would remark that, after using method (A), I feel confident that it is still capable of much higher accuracy than that shown above.

In conclusion I would express my best thanks to Dr. Glazebrook for most valued advice and help.

XLVIII. Lloyd's Fringes for Internal Retlexion, and the Change of Phase of Ordinarily Reflected Light. By P. V. Bevan, M.A., Fellow of Trinity College, University Demonstrator in Experimental Physics, Cambridge†.

\section{[Plate XIII.]}

$\mathrm{TT}^{\mathrm{T}}$ is generally assumed that when light is reflected externally, as in the applications of the wave theory to Newton's rings, there is a loss of half an undulation. The evidence for this is the single mirror fringes obtained by Lloyd, and experiments with the three mirrors of Fresnel made by Jamin. In the first case we have interference of

* The main probable errors in (C) seem to be due to three causes, namely : the variations (natural and other) in the earth's horizontal magnetic field : some uncertainty in the time measurements; and the magnetizing effect of the current on the galvanometer needles, not necessarily the same for a steady current and a sudden rush.

+ Communicated by the Author. 


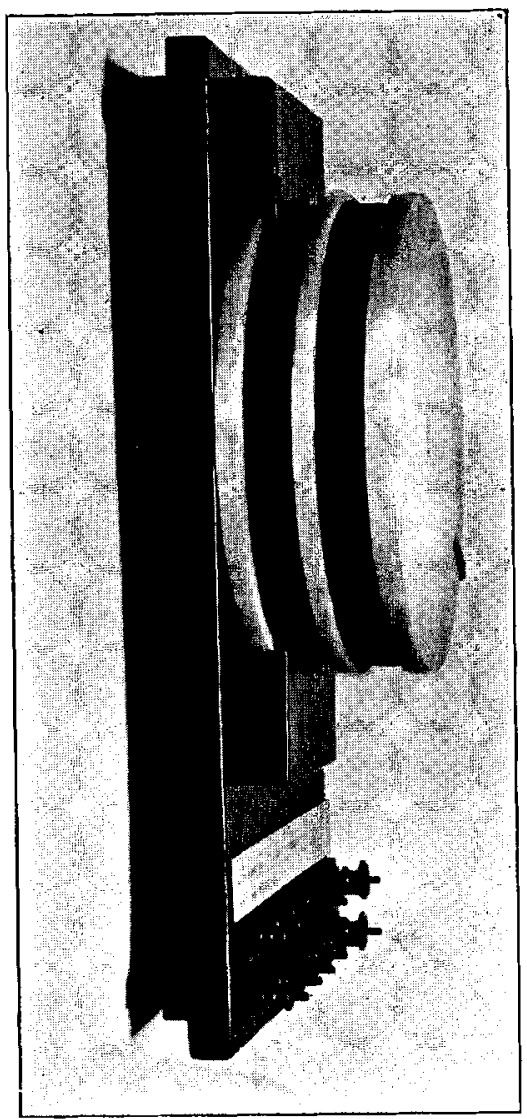

